\title{
Bolted joints in three axially braided carbon fibre/epoxy textile composites with moulded-in and drilled fastener holes
}

DOI:

10.1007/s10443-016-9542-z

\section{Document Version}

Accepted author manuscript

Link to publication record in Manchester Research Explorer

Citation for published version (APA):

Atas, A., Gautam, M., Soutis, C., \& Potluri, P. (2016). Bolted joints in three axially braided carbon fibre/epoxy textile composites with moulded-in and drilled fastener holes. Applied Composite Materials.

https://doi.org/10.1007/s10443-016-9542-z

\section{Published in:}

Applied Composite Materials

\section{Citing this paper}

Please note that where the full-text provided on Manchester Research Explorer is the Author Accepted Manuscript or Proof version this may differ from the final Published version. If citing, it is advised that you check and use the publisher's definitive version.

\section{General rights}

Copyright and moral rights for the publications made accessible in the Research Explorer are retained by the authors and/or other copyright owners and it is a condition of accessing publications that users recognise and abide by the legal requirements associated with these rights.

\section{Takedown policy}

If you believe that this document breaches copyright please refer to the University of Manchester's Takedown Procedures [http://man.ac.uk/04Y6Bo] or contact uml.scholarlycommunications@manchester.ac.uk providing relevant details, so we can investigate your claim.

\section{OPEN ACCESS}




\section{Bolted Joints in Three Axially Braided Carbon Fibre/Epoxy Textile Composites with Moulded-in and Drilled Fastener Holes}

Akın Ataş, $1,{ }^{*}$

Phone +90266 6121194/5106

Email a.atas@balikesir.edu.tr

Mayank Gautam, 2

Constantinos Soutis, ${ }^{2}$

Prasad Potluri, 2

1 Department of Mechanical Engineering, Balıkesir

University, 10145 Balıkesir, Turkey

2 Northwest Composite Centre, School of Materials, University of

Manchester, Manchester, M13 9PL UK

\section{Abstract}

Experimental behaviour of bolted joints in triaxial braided $\left(0^{\circ} / \pm 45^{\circ}\right)$ carbon fibre/epoxy composite laminates with drilled and moulded-in fastener holes has been investigated in this paper. Braided laminates were manufactured by vacuum infusion process using $12 \mathrm{~K}$ T700S carbon fibres (for bias and axial tows) and Araldite LY-564 epoxy resin. Moulded-in fastener holes were formed using guide pins which were inserted in the braided structure prior to the vacuum infusion process. The damage mechanism of the specimens was investigated using ultrasonic C-Scan technique. The specimens were dimensioned to obtain a bearing mode of failure. The bearing strength of the specimens with moulded-in hole was reduced in comparison to the specimens with drilled hole, due to the increased fibre misalignment angle following the pin insertion procedure. An improvement on the bearing strength of mouldedin hole specimens might be developed if the specimen dimensions would be prepared for a net-tension mode of failure where the fibre misalignment would not have an effect as significant as in the case of bearing failure mode, but this mode should be avoided since it leads to sudden catastrophic failures. 


\section{Keywords}

Triaxial braided composite laminates

Bolted joints

Moulded-in hole

\section{Introduction}

Two-dimensional (2-D) multidirectional carbon fibre reinforced plastic (CFRP) composite laminates (made of unidirectional prepreg layers and generally referred to as "tape" laminates) are currently dominating the aerospace structural parts mainly due to their exceptional in-plane stiffness and strength properties and good fatigue resistance. However, tape laminates may suffer from poor damage tolerance and low interlaminar strength as well as relatively high material and manufacturing costs. Extensive research efforts have been devoted to investigate the use of carbon fibre based textile composites in aerospace industry as an alternative to the tape laminates since 1990s [1, 2, 3, 4, 5, 6]. Textile composites use fibre preforms produced by textile forming technologies such as braiding, weaving and knitting. They offer lower manufacturing cost, easy handling, near-net shape manufacturability, improved out-of-plane stiffness, strength and toughness at the expense of slight to moderate reduction in the inplane stiffness and strength properties in comparison to the tape laminates.

Braiding is a special textile preforming technology which allows complex, nearnet shape part manufacturing with fibre continuity at the edges and around the holes [7]. It enables the integral design concept for the reduction of structural joints by minimising the number of individual parts. However, increased tooling cost for the integral parts, restrictions on logistic, handling, inspection and maintenance requirements limit the feasible size of composite structures [8]. For instance, each Airbus A380 consists of around 4 million individual components produced by 1500 companies from 30 countries around the world [9].

Various configurations of bonded, bolted and bonded/bolted joints are extensively used in aerospace structures based on the specific requirements of particular applications. Mechanically fastened joints (pinned, bolted and riveted) are widely used to fasten highly loaded composite components to other composite or metallic parts. They are easy to assemble and can be disassembled when required for inspection and/or maintenance purposes without imparting damage $[10,11,12]$. Yet, they are the Achilles' heel of the composite structures due to the stress concentrations created by fastener holes. Based on standard engineering design procedures, the maximum efficiency of the optimised bolted 
joints in composite laminates (load capacity of the joint/ultimate laminate strength) is approximately $50 \%$. In other words, the designer surrenders to the fact that the load capacity of a composite part is reduced by half no matter how exceptional its material properties are. All research and development efforts for improved material properties and performance are compromised at the critical mechanical joint locations. Therefore, developing innovative joining technologies with a higher efficiency is essential in order to exploit the advantages offered by the composite materials.

Moulded-in holes have been considered as an alternative for increasing the joint efficiency of composite components since the fibre discontinuity at the fastener holes due to the drilling process is one of the main contributors for the strength reduction. Open hole (notched) specimens and mechanical joints in unidirectional, woven and braided textile composites with various fibre, resin systems and manufacturing methods under several loading conditions have been the focus of several investigations.

The moulded-in specimens with quasi-isotropic lay-ups, made from unidirectional CFRP prepregs, exhibited approximately $30 \%$ higher strength and almost $100 \%$ lower maximum strain levels than the drilled hole counterparts when subjected to open hole tension tests [13]. In addition, a gradual failure was observed in the moulded-in hole specimens while a sudden failure shortly after the failure onset occurred in the drilled hole specimens. Significant improvements have been reported also for notched and bearing strength of woven fabric reinforced composite laminates with moulded-in holes [14, 15]. Fibre continuity at the side edges of the braided specimens also play an important role on the strength of notched specimens. The tensile loaddisplacement curves of the centre notched specimens were more compliant in the case of cut side edges due to the subcritical damage mechanisms developed at the edges [16]. In case of bolted joint tests of biaxial braided composites, bearing failure mode was observed in all of the moulded-in hole specimens regardless of the specimen geometry. For the drilled hole specimens, shear-out and net-tension modes were developed when critical minimum dimensions were reached for the edge distance and the width of the specimens, respectively [17]. Braided cylinders with moulded-in and drilled holes have also been used to investigate the effect of drilling process on the tension, compression and bearing behaviour. Under uniaxial tensile and compressive loading, the specimens with moulded-in hole experienced significantly reduced strain concentrations due to the additional local longitudinal stiffness provided by the braid yarns. Pin bearing strength of the braided hole specimens was about 1.8 times higher than that of the drilled hole specimens [18]. The moulded-in hole specimens in triaxial braided glass fibre reinforced epoxy composites exhibited similar or 
lower bearing strength than the drilled hole for the flat specimens. It was attributed to the disturbance in fibre arrangement around the braided hole [19].

This study is an integral part of a project in which the pseudo-plastic behaviour of flattened tubular braided fabric (sleeve) laminates has been investigated as a function of the reinforcing axial fibre tows [20]. The paper focuses on the bolted joint response of the triaxial braided carbon fibre/epoxy composite laminates with moulded-in and drilled fastener holes.

\section{Experimental Procedure}

\subsection{Materials and Manufacturing Process of the Specimens}

Two-dimensional triaxial tubular braid fabric sleeves were formed by using a 48 carrier maypole type braiding machine as shown in Fig. 1. During the braiding process, one set of bobbin carriers move in clock-wise and one set in anticlockwise direction, in form of a 'serpentine' motion. The serpentine motion of bobbin carriers, form the principle of interlacement in a biaxial braid. The speed of bobbin carrier motion and the speed of take-up device control the braid angle $\left( \pm \theta^{\circ}\right)$. An additional set of yarn or tows can be inserted during braiding, through the guides, located between the bobbin carriers, in $0^{\circ}$ (axial) direction i.e. along the braid axis, resulting in formation of triaxial braided structure $\left(+\theta^{\circ} / 0^{\circ} /-\theta^{\circ}\right)$. The inserted axial tows were kept straight during the braiding process, by keeping the feed tension high (150 g), which was also same as the feed tension in the bobbin carriers.

\section{Fig. 1}

Representation of 48 carrier braiding machine with 24 axial guides, to produce a triaxial braid with braid angle of $\pm 45^{\circ}$, with 12 axial tows (alternate axial tow guides left empty) 


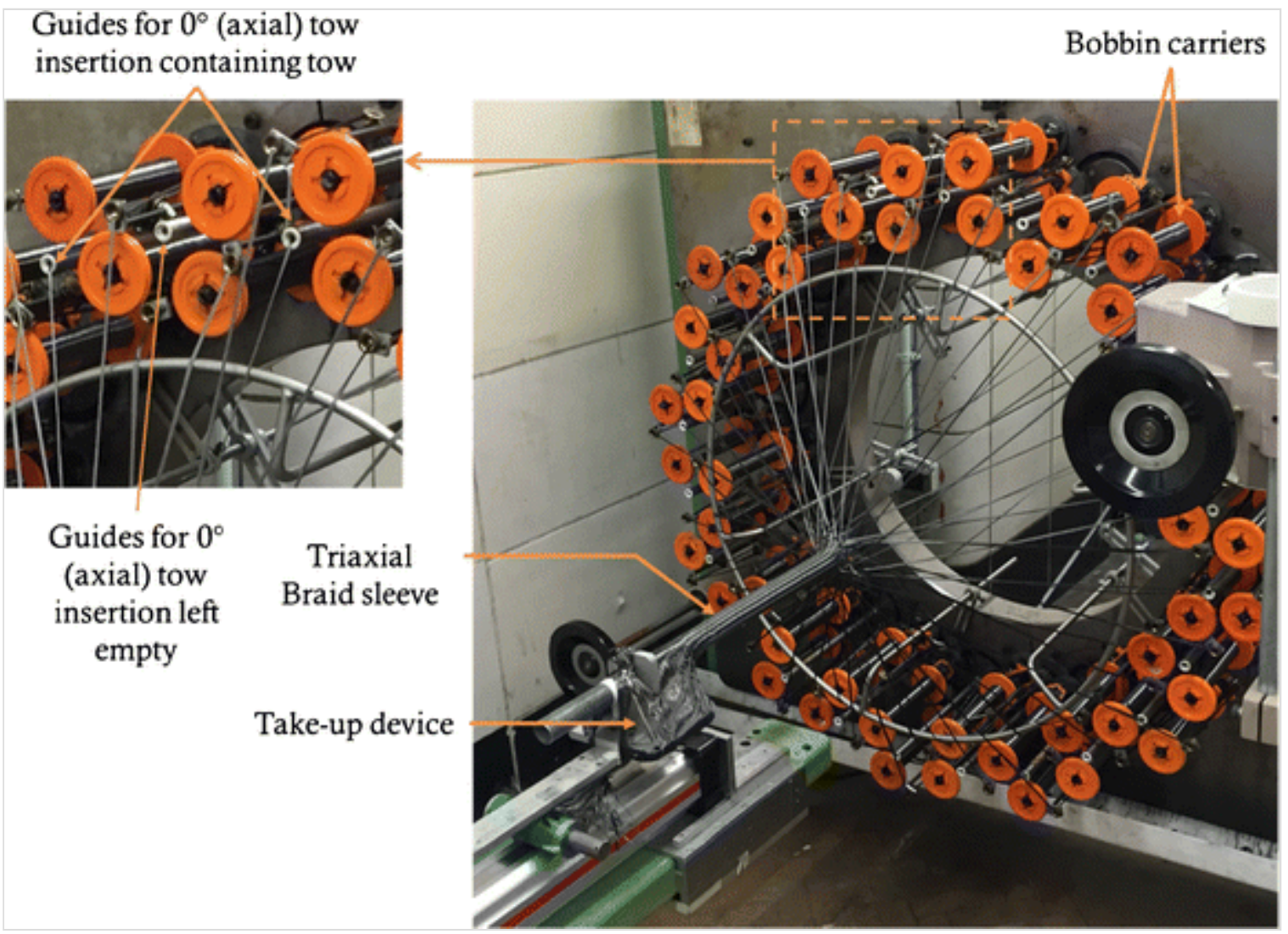

The fibre type used for biaxial (or bias) and axial tows in the braid were T700S high strength, standard modulus $12 \mathrm{~K}$ carbon fibre tows [22]. The over-braided sleeve was formed on a $25.4 \mathrm{~mm}$ diameter aluminium cylindrical mandrel, as a single layer with regular (2/2) braid topology. Two type of braid sleeves (with 48 biaxial tows) were produced, one with six and other with twelve axial tows that were equally spaced around the circumpherence of the mandrel. The percentage of axial tows was $11.1 \%$ and $20 \%$ in the triaxial braid sleeves with six and twelve axial tows, respectively. The schematics of the type of braid fabrics produced, which were generated using TexGen software [23] have been shown in Fig. 2.

Fig. 2

Schematic representation of braid patterns generated using TexGen open source software [23] for a six axial tows and $\mathbf{b}$ twelve axial tows

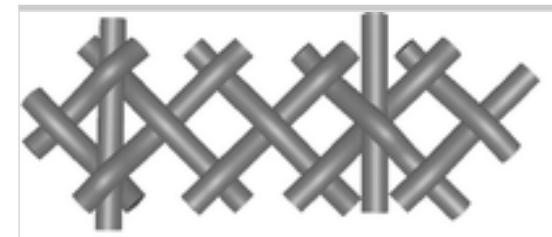

(a)

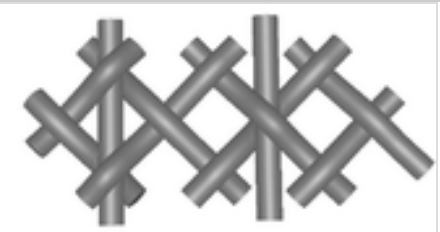

(b)

Following the braiding process, the tubular braid sleeve was carefully removed from the mandrel without any distortion of the braid sleeve, and then flattened using rigid platens with special care given to the precise alignment of the axial 
tows at the side edges of the flattened specimens. This resulted in a balanced, symmetrical fabric with continuous fibres at the side edges of the specimens.

The width of the flattened specinmens was approximately $40 \mathrm{~mm}$ due to the avardo according to ASTM D5961 standard [24]; this alteration was assumed to be negligible on the comparative results since all specimens (drilled and moulded-in fastener holes) were braided using the same mandrel diameter and consequently have the same specimen width. The effect of the flattening process on the braid angle of the tubular braid sleeve was found to be marginal an increase in braid angle of $1.5^{\circ}$ deviation at the sleeve edges.

The flattened tubular braid sleeves with moulded-in or drilled holes were impregnated by vacuum infusion process using Araldite LY564/Aradur 2954 epoxy resin system [25]. Material property details are presented in Tables 1 and 2 . The resin-infused fabrics were cured at $80{ }^{\circ} \mathrm{C}$ for $2 \mathrm{~h}$ and post-cured at $140{ }^{\circ} \mathrm{C}$ for $8 \mathrm{~h}$ according to the manufacturer's recommendation.

\section{Table 1}

T700S fibre properties [22]

\begin{tabular}{|c|c|c|c|c|}
\hline $\begin{array}{l}\text { Density } \\
\left(\mathrm{g} / \mathrm{cm}^{3}\right)\end{array}$ & $\begin{array}{c}\text { Young's } \\
\text { Modulus (GPa) }\end{array}$ & $\begin{array}{c}\text { Tensile strength } \\
\text { (MPa) }\end{array}$ & $\begin{array}{c}\text { Failure } \\
\text { strain }(\%)\end{array}$ & $\begin{array}{c}\text { Filament } \\
\text { diameter }(\mu \mathrm{m})\end{array}$ \\
\hline 1.80 & 230 & 4900 & 2.1 & 7 \\
\hline
\end{tabular}

Table 2

Araldite LY 564/Aradur 2954 epoxy resin system properties [25 ]

\begin{tabular}{|c|c|c|c|c|}
\hline $\begin{array}{l}\text { Density } \\
\left(\mathrm{g} / \mathrm{cm}^{3}\right)\end{array}$ & $\begin{array}{c}\text { Young's Modulus } \\
\text { (GPa) }\end{array}$ & $\begin{array}{c}\text { Tensile strength } \\
\text { (MPa) }\end{array}$ & $\begin{array}{c}\text { Failure } \\
\text { strain }(\%)\end{array}$ & $\begin{array}{c}\text { Poisson's } \\
\text { ratio }(\mu)\end{array}$ \\
\hline $1.1-1.2$ & $2.55-2.65$ & $71-77$ & $4.5-5.5$ & 0.35 \\
\hline
\end{tabular}

The mechanical properties of B0645 and B1245 specimen configurations have been depicted in Table 3, where 06 and 12 represent the number of axial tows while 45 represents the braid angle $\left(45^{\circ}\right)$ for each case. Two groups of test specimens with drilled (denoted by D0645 and D1245) and moulded-in fastener holes (denoted by M0645 and M1245) were manufactured in order to investigate the joint performance as a function of the hole forming procedure. In the first group, the fastener holes were drilled using carbide tipped drill bits with sacrificial backing plates in order to reduce the delamination damage. The holes were drilled at a distance of $18 \mathrm{~mm}$ from the free edge of the specimens $(e / d=3)$. The moulded-in fastener holes, in the second group, were formed by 
manually inserting the release agent applied guide pins to the braided fabrics before the vacuum bagging process. The pictures of a braided fabric without a fole and with a guide pin are shown in fig. 3. The fastenter hole was formed by Specimen in Axial Modulus a conleal stee pin which waspenoved prior to therperplacement with the guide pin. Rectangular aluminium blocks were placed on top of the hole area in order to provide a uniform consolidation and prevent resin rich areas due to the protruding pin as shown in Fig. 3. The guide pins were fixed onto the steel mould using instant adhesive. The total fibre volume fraction of the laminates was found to be approximately $55 \%$ which was determined using acid digestion procedure according to ASTM D3171 standard [26].

Table 3

Mechanical properties of triaxially braided composite laminates [20]

\begin{tabular}{|l|l|l|l|}
\hline \multicolumn{1}{|c|}{$\begin{array}{c}\text { Specimen } \\
\text { reference }\end{array}$} & \multicolumn{1}{|c|}{$\begin{array}{c}\text { Axial Modulus } \\
\text { (GPa) }\end{array}$} & $\begin{array}{c}\text { Tensile strength } \\
\text { (MPa) }\end{array}$ & \multicolumn{1}{c|}{$\begin{array}{c}\text { Failure strain } \\
\text { (\%) }\end{array}$} \\
\hline B0645 & $19 \pm 2$ & $195 \pm 31$ & $8 \pm 2$ \\
\hline B1245 & $22 \pm 1$ & $249 \pm 31$ & $1.3 \pm 0.7$ \\
\hline
\end{tabular}

\section{Fig. 3}

Braided fabric architecture $\left(+45^{\circ}\right.$ and $-45^{\circ}$ bias tows are visible on the surface, $\theta$ refers to braid angle) without a hole and with the guide pin. Distortion of the tows around the pin is clear
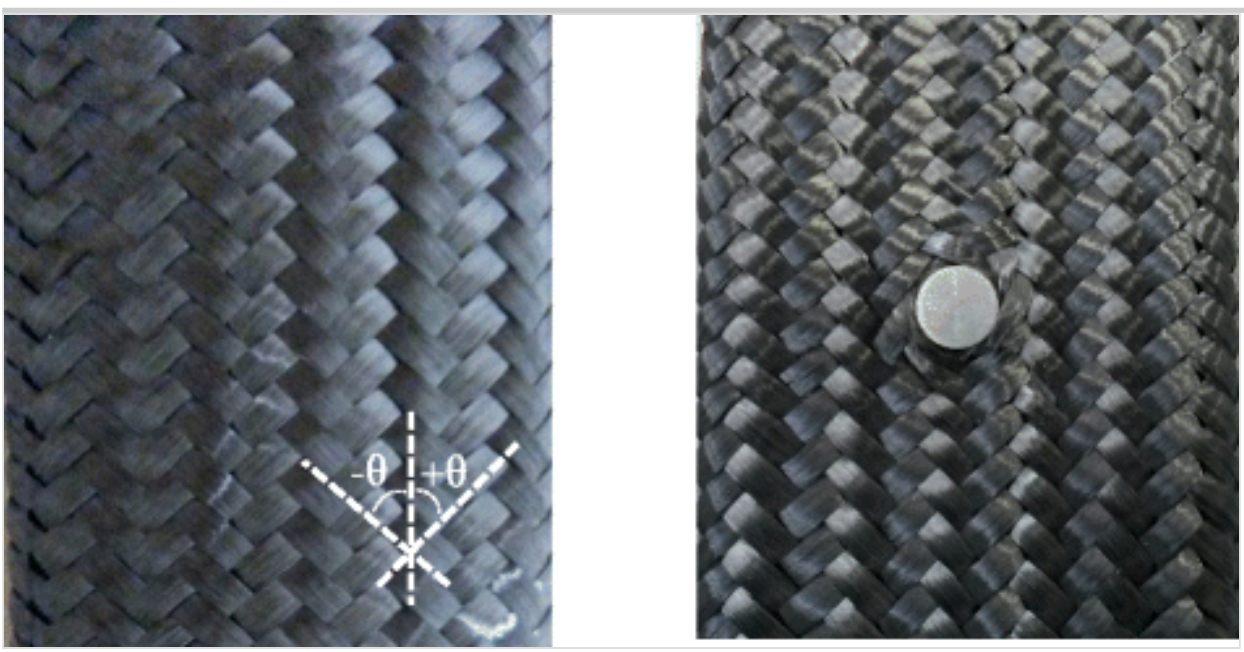

\subsection{Single Fastener Double-Shear Bearing Tests and Investigation of Damage Mechanisms}

Typical specimen geometry of a pin joint in a composite laminate is shown in Fig. 4 with definitions of the width $(w)$, free edge distance $(e)$, hole diameter $(d)$ and thickness $(t)$. The $x-y$ and $1-2$ coordinate systems define the global laminate 
and local material coordinate systems, respectively. The angles $\varphi$ and $\theta$ define the layer orientation angle with respect to the $x$ (loading) axis and the circumferential co-ordinate direction around the hole boundary, respectively.

\section{Fig. 4}

Geometrical definitions of a pin joint in a composite laminate

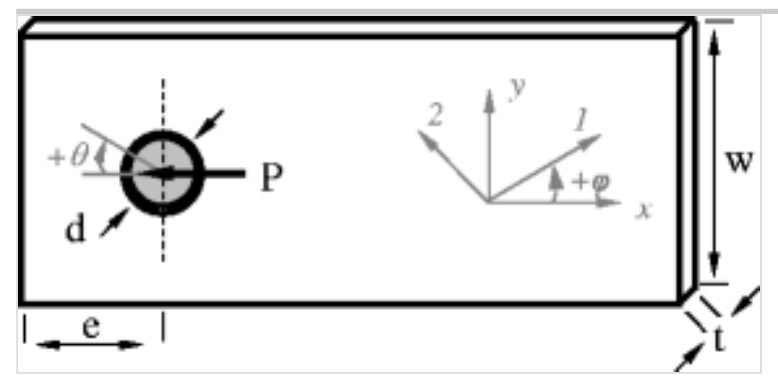

Typical in-plane critical stress distributions around a pin-loaded hole are the normal stresses at the net-tension plane, shear stresses at the shear-out plane and the radial bearing stresses at the bearing plane as illustrated in Fig. 5 [27]. The stresses decay rapidly away from the hole boundary at the net-tension and shearout planes with increased $w$ and $e$ respectively, and maximum radial compression (bearing) stress develops at the bearing plane due to the fastener/hole interaction. In the geometrical aspect, net-tension mode is observed when the specimen width is not wide enough to relieve the high normal stress gradients (low $w / d$ ratio). Shear-out mode is observed in laminates with adequate width against the net-tension mode but insufficient free edge distance to relieve the high shear stresses developed at the shear-out plane (low $e / d$ ratio). In the net-tension and shear-out failure modes, the compressive stresses developed at the bearing plane are not high enough to cause significant fibre failure before those net-tension or shear-out modes occur. Bearing mode is caused by the compressive stresses and includes matrix cracking, fibre micro-buckling and kinking with a significant amount of delamination.

Fig. 5

Influence of geometrical parameters on the failure of pin joints [27] 


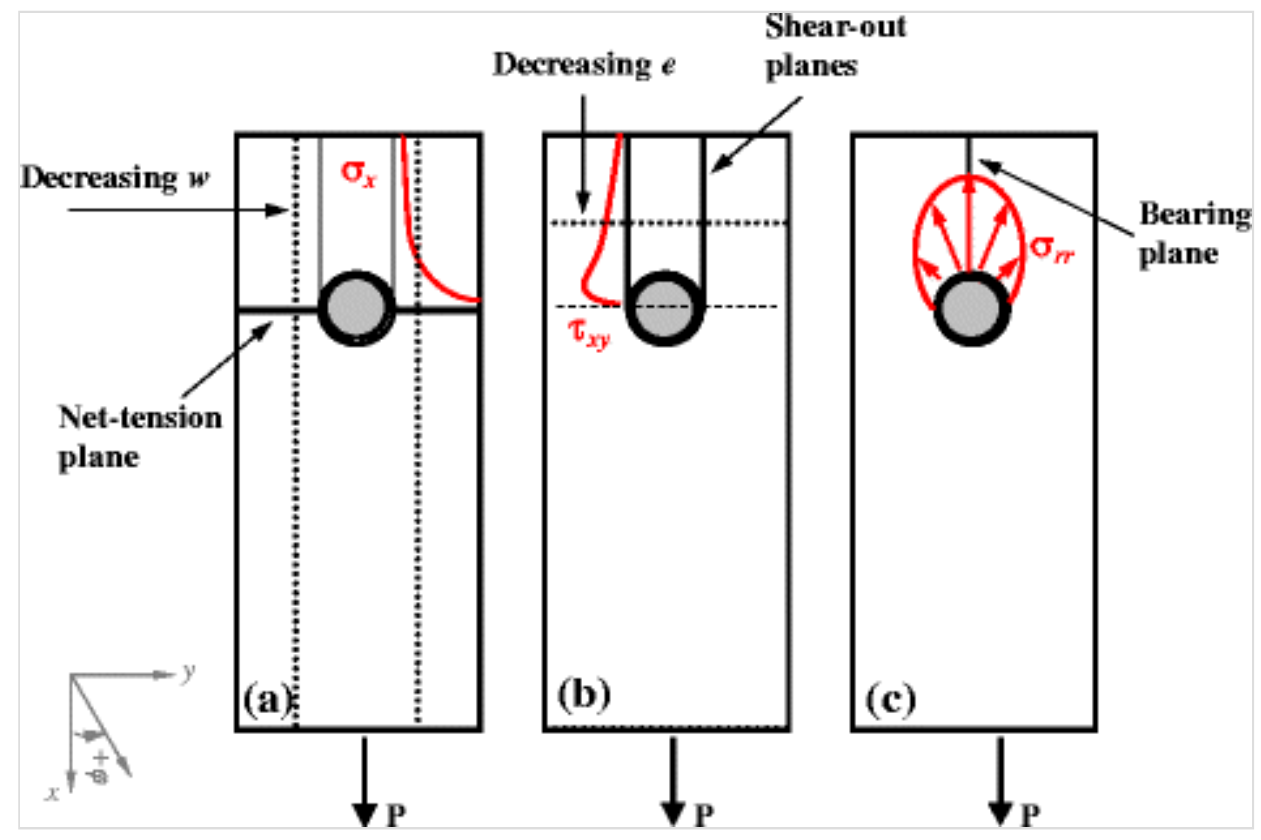

Tests were conducted at room temperature with an Instron 5982 electromechanical testing machine (fitted with a $100 \mathrm{kN}$ load cell and hydraulic grips) at a $2 \mathrm{~mm} / \mathrm{min}$ loading rate while the applied load and cross-head displacement were recorded by a data acquisition system. In order to prevent the masking of the true damage mechanisms due to large hole deformations, tests were stopped after a significant load drop (approximately $30 \%$ ) observed in the load-displacement curve [24]. A2 grade stainless steel bolts were used for the tests with a clamping torque of $2.8 \mathrm{Nm}$ for all specimens. Five specimens were tested for each case.

Following the tests, the specimens were inspected using ultrasonic C-Scan technique with a Midas Water Jet C-Scan system. This is a widely used and well established non-destructive damage detection method for fibre reinforced composite materials $[28,29]$.

\section{Results and Discussions}

\subsection{Bearing Stress-Bearing Strain Curves}

The representative bearing stress-bearing strain curves of drilled hole and moulded-in hole specimens reinforced with six axial tows (0645) have been shown in Fig. 6. Bearing stress $\sigma_{b}$ is calculated as $\sigma_{b}=P / d t$ where $P$ is the load, $d$ is the hole diameter and $t$ is the thickness of the laminate. Bearing strain was calculated for each displacement value according to ASTM D5961 [24]. Both specimens exhibit a predominantly linear portion until the first significant load drop is reached. The D0645 specimen develops a more gradual failure process due to the local machining damages developed during the drilling procedure which cause fluctuations on the bearing stress-bearing strain curve. This local 
stress re-distributions reduce the stress concentrations around the hole boundary and contribute to the higher strength of the D0645 drilled hole specimen despite the reduced stiffness of the joint after its first peak point. The M0645 specimen reaches a plateau at a load level which is well below the D0645 specimen. There is a relatively lower stiffness zone up to around $0.07 \%$ bearing strain in the D0645 specimen curve because of the bolt settling into the fastener hole and overcoming the friction forces between the laminate and washer surfaces. The first significant load drop observed around $0.24 \%$ and $0.35 \%$ bearing strain levels for the M0645 and D0645 specimens, respectively. The initial stiffness of both D0645 and M0645 specimens are quite close to each other until the first peak stress level of the M0645 specimen. Following these first peak points, the M0645 specimen does not show a noteworthy increase in the load carrying capacity while approximately a $20 \%$ increase is observed for the D0645 specimen.

\section{Fig. 6}

Representative bearing stress-bearing strain curves for drilled hole (D0645) and moulded-in hole (M0645) specimens with 6 axial fibre tows

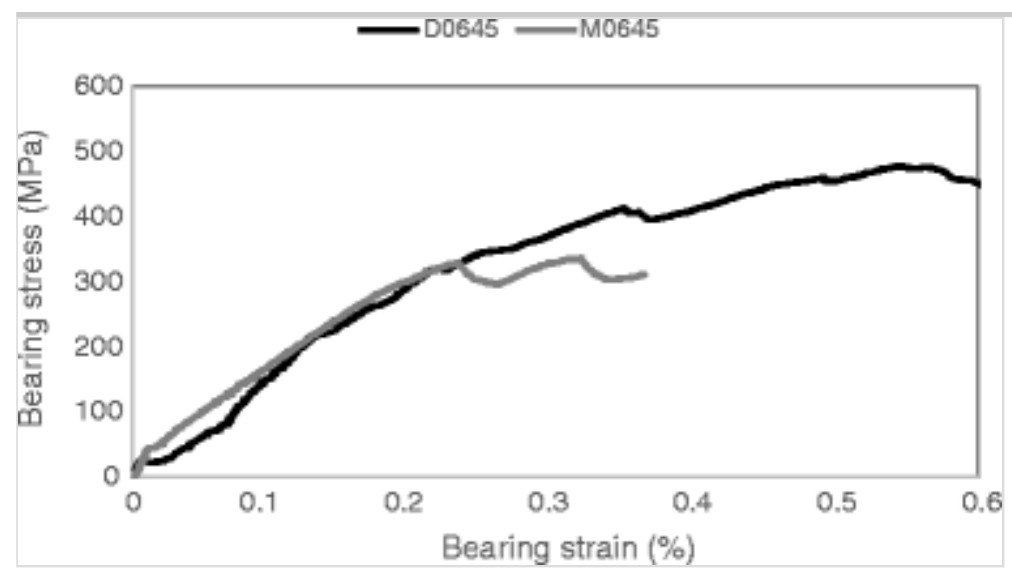

Figure 7 shows the representative bearing stress-bearing strain curves of drilled hole and moulded-in hole specimens reinforced with twelve axial tows (1245).

\section{Fig. 7}

Bearing stress-bearing strain curves for representative drilled hole (D1245) and moulded-in (M1245) specimens with 12 axial fibre tows 


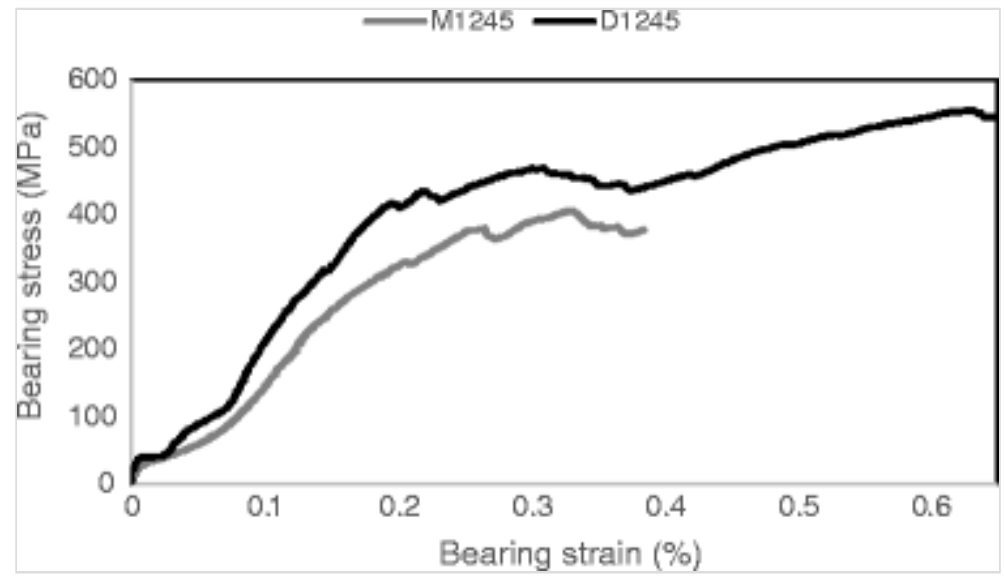

The drilled hole specimen D1245 shows an increased strength over the mouldedin hole counterpart as in the case of six axial fibre reinforced laminates. In contrast to the similar initial stiffness values of the 0645 specimens in both groups, D1245 specimen has a significantly higher initial stiffness than the M1245 specimen. D1245 specimen also shows a clear plateau which is not observed in the D0645 specimen. This is a result of the damage mechanism peculiar to bearing mode in which the most of the applied load is transferred to the fibres at the bearing plane through the bolt shank as shown in Fig. 5 . Although the fibres are cut in the drilled hole specimens, the orientation of the fibres are not disturbed. Therefore, the stiffness and the strength of the D1245 specimens are higher than the M1245 specimens. Figure 8 illustrates the $\pm 45^{\circ}$ fibre tow patterns around a moulded-in and a drilled fastener hole. It is clear that the insertion of the guide pin in order to form the moulded-in hole increase the angle of the fibre tows considerably with respect to the loading direction.

Although the fibre continuity is violated in the case of specimens with a drilled hole, it does not have a negative effect on the bearing strength of the joints.

Because, the failure occurs mainly as a result of the compressive bearing stresses at the bearing plane where the fibre tow angle has the dominant influence.

\section{Fig. 8}

Schematic representation of $\pm 45^{\circ}$ fibre tow patterns around a moulded-in (left) and a drilled fastener hole (right) [16]

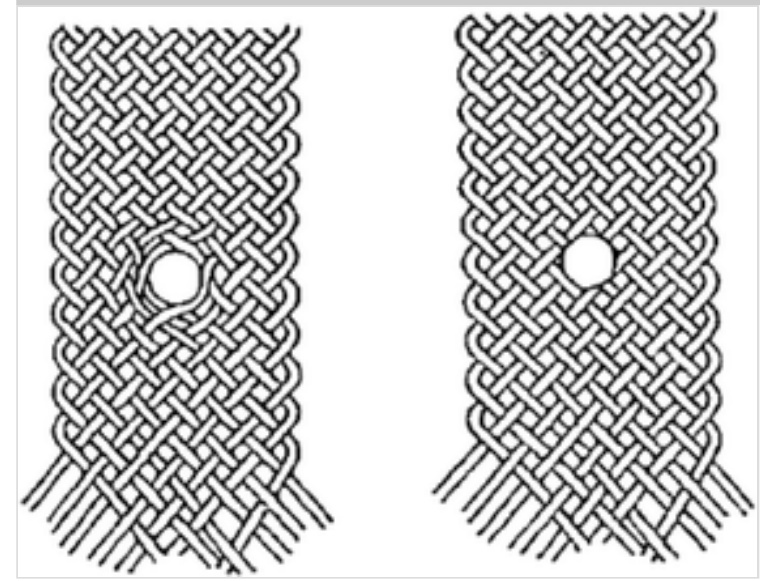


A brief information on the compressive behaviour of the fibre reinforced composite materials is given below in order to explain the dominant effect of

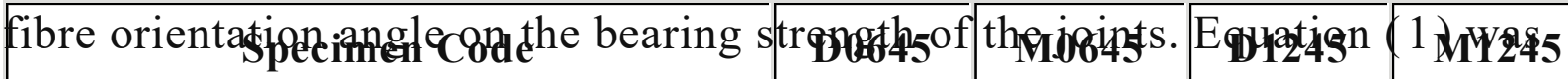
proposed [30] for the compressive strength $\sigma_{C}$ of fibre reinforced composite laminates, where $\tau_{Y}$ is the shear yield strength of the composite and the $\bar{\phi}$ is the initial maximum angular fibre misalignment.

$$
\sigma_{c}=\tau_{Y} / \bar{\phi}
$$

It is clear that the compressive strength of a composite laminate is inversely proportional to the initial fibre misalignment. Therefore, the bearing strength of the moulded-in hole specimens (M0645 and M1245) are lower than the drilled hole counterparts (D0645 and D1245) since the fibre misalignment was significantly increased due to the pin insertion process for the moulded-in specimens as shown in Fig. 3 .

\subsection{Bearing Strength of the Joints}

The average bearing strength of the bolted joints have been reported in Table 4 . Bearing strength of the specimens was calculated as $\sigma=P_{\text {max }} / d t$ where $P_{\text {max }}$ is the maximum load sustained by the joint. The bearing strength of the drilled-hole specimens is almost the same for both the six and twelve axial tow reinforced composite plates. This is a result of the specimen geometry which facilitates the bearing mode of failure. High compressive stresses at the bearing plane cause the failure of the specimen, where the number of the axial reinforcing tows have no direct influence, as the axial tows placed equidistant throughout the tubular braid, do not come in direct contact with the moulded in or machined holes. When the fastener hole is drilled, the bearing stresses mainly carried by the $\pm 45^{\circ}$ layers ahead of the bolt shank. Therefore, both of the drilled hole specimens have a similar average bearing strength.

\section{Table 4}

Average bearing strength values for drilled (D0645, D1245) and moulded-in (M0645, M1245) specimens

\begin{tabular}{|l|l|l|l|l|}
\hline \multicolumn{1}{|c|}{ Specimen Code } & \multicolumn{1}{|c|}{ D0645 } & M0645 & D1245 & M1245 \\
\hline Average Bearing strength (MPa) & 534.2 & 356.3 & 535.7 & 439.5 \\
\hline CoV $(\%)$ & $(5.1)$ & $(5.2)$ & $(5.4)$ & $(8.4)$ \\
\hline
\end{tabular}


On the other hand, the bearing strength of specimens with moulded-in hole with 12 axial tows is significantly higher than the 6 axial tow reinforced counterparts. This behaviour can be explained by using the bearing stress-bearing strain curves shown in Figs. 6 and 7. M0645 specimen follows a relatively linear bearing stress-bearing strain curve up to the first peak point, whereas the M1245 specimen clearly exhibits a nonlinear behaviour. This nonlinearity stems from the axial tows surrounding the fastener hole. In M0645 specimen, the axial tows are located further away from the hole boundary and were kept out of the area with dislocated fibres when the guide pin was inserted.

\subsection{Damage Mechanisms}

Damage mechanisms of the tested specimens were inspected using ultrasonic CScan technique with a Midas Water Jet C-Scan system. The extent of the intraand interlaminar damage around the hole boundaries captured at the ultimate load of the joints. In general, the damage is spread around the bearing planes and between the shear-out planes. Figure 9 shows the damage maps around the tested specimens at the final failure load. Blue colour in the figures indicates the damage zones including intra and interlaminar damage mechanisms.

\section{Fig. 9}

C-Scan damage maps of specimens around the hole boundaries at the final failure load. Blue colour indicates the damage zones including intra and interlaminar damage mechanisms 

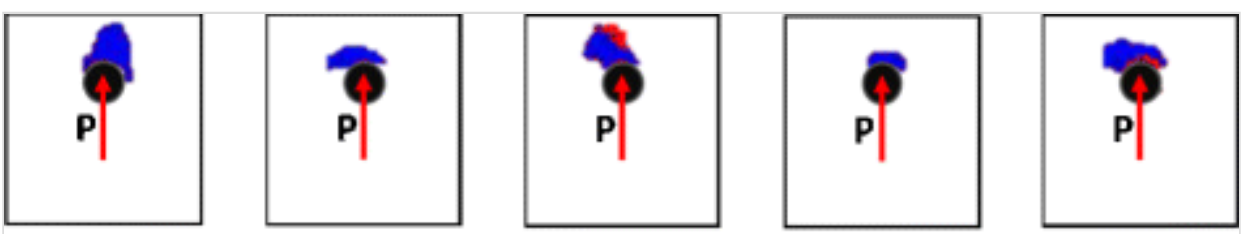

(a) D0645 specimens
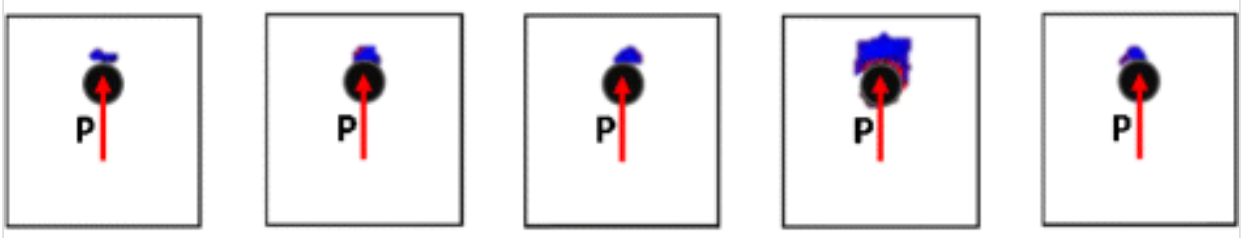

(b) M0645 specimens
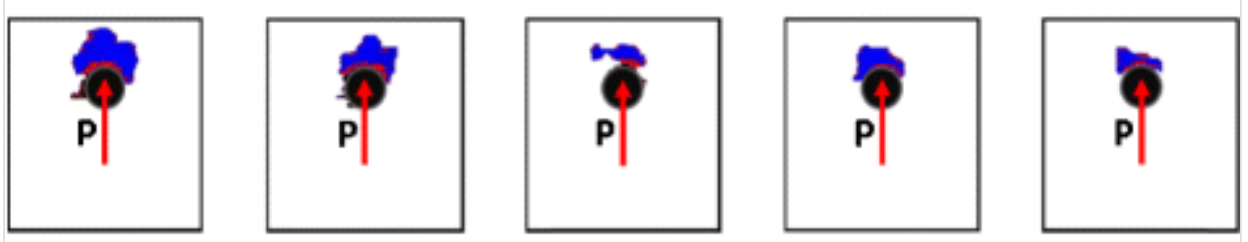

(c) D1245 specimens
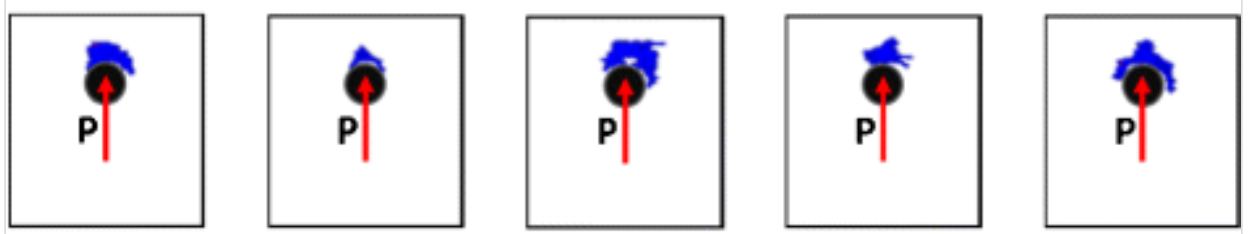

(d) M1245 specimens

The specimens with drilled holes exhibit a greater amount of damage zone in accordance with the higher bearing strain levels (see Figs. 6 and 7) due to the gradual damage accumulation. It facilitated the stress re-distribution following the intralaminar and interlaminar subcritical damage modes. Therefore, the bearing strength of the joints reached higher levels. The moulded-in hole specimens, however, reaches a plateau where the continuous fibre tows ahead of the bolt shank takes over the applied load. These bias tows reduce the amount of stress re-distribution within the compliant matrix material which is the result of the smaller damage extent of the moulded-in hole specimens in Fig. 9.

\section{Conclusions}

The present study focused on the bearing mode of failure where the width $(w)$ and free edge distance $(d)$ of the specimens were adjusted so that the critical stresses (compressive) occurred at the bearing plane. All the specimens with moulded-in hole experienced lower bearing strength than the specimens with drilled holes due to the increased fibre tow orientation angles at the bearing plane. If the geometrical dimensions would be arranged to cause a net-tension failure mode, then the moulded-in hole technique may provide a higher bearing strength. Because, the critical stresses would be developed around the nettension plane (see Fig. 5) where the fibre continuity due to the moulded-in hole 
manufacturing procedure would have increased the joint strength. This though could lead to sudden catastrophic failures, giving little warning to the operator, hence progressive damage might be preferable. Further investigation is required to verify the damage mechanism and joint strength for various geometrical ratios.

Despite being relatively labour extensive, moulded-in fastener holes have a potential to reduce the manufacturing cost by avoiding the drilling time and tooling cost. Development of an automated hole forming and mould placement method during fabrication stage is planned for further investigation of this hole forming technique.

\section{Acknowledgments}

The scientific and technological research council of Turkey (TÜBİTAK) is gratefully acknowledged for the post-doctoral scholarship granted to the first author.

\section{References}

AQ1

1. Pastore C.M., Masters J.E., Foye R.L., Gowayed Y.A.: Mechanical properties of triaxially braided composites: experimental and analytical results. J. Compos. Technol. Res. 15(2), 112-122 (1993)

2. Naik RA. Analysis of woven and braided fabric reinforced composites. (1994)

3. Portanova M, Masters J.: Standard methods for bolt-bearing testing of textile composites. (1995)

4. Portanova MA, Masters J.: Standard methods for open hole tension testing of textile composites. (1995)

5. Portanova MA.: Standard methods for unnotched tension testing of textile composites. (1995)

6. Masters JE, Portanova MA.: Standard test methods for textile composites. (1996)

7. Potluri P.: Braiding. Wiley Encyclopedia of Composites. (2012) 
8. Fink A., Camanho P., Andrés J., Pfeiffer E., Obst A.: Hybrid CFRP/titanium bolted joints: performance assessment and application to a spacecraft payload adaptor. Compos. Sci. Technol. 70(2), 305-317 (2010)

9. http://www.airbus.com/presscentre/corporate-information/key-documents/ Accessed 27 Nov 2015

10. Atas A., Mohamed G., Soutis C.: Modelling delamination onset and growth in pin loaded composite laminates. Compos. Sci. Technol. 72(10), 1096-1101 (2012)

11. Atas A., Mohamed G.F., Soutis C.: Progressive failure analysis of bolted joints in composite laminates. Plastics, Rubber and Composites. 41(4/5), 209$214(2012)$

12. Ataş A., Soutis C.: Strength prediction of bolted joints in CFRP composite laminates using cohesive zone elements. Compos. Part B. 58, 25$34(2014)$

13. Zitoune R., Crouzeix L., Collombet F., Tamine T., Grunevald Y.-H.: Behaviour of composite plates with drilled and moulded hole under tensile load. Compos. Struct. 93(9), 2384-2391 (2011)

14. Chang L.-W., Yau S.-S., Chou T.-W.: Notched strength of woven fabric composites with moulded-in holes. Composites. 18(3), 233-241 (1987)

15. Nejhad M.G., Chou T.: Compression behaviour of woven carbon fibrereinforced epoxy composites with moulded-in and drilled holes. Composites. 21(1), 33-40 (1990)

16. Fujita A., Maekawa Z., Hamada H., Yokoyama A.: Mechanical behavior and fracture mechanism in flat braided composites. Part 2: braided flat bar with a circular hole. J. Reinf. Plast. Compos. 11, 618-632 (1992)

17. Fujita A., Hamada H., Maekawa Z., Ohno E., Yokoyama A.: Mechanical behavior and fracture mechanism in flat braided composites. Part 3: mechanically fastened joint in flat braided bar. J. Reinf. Plast. Compos. 13(8), 740-755 (1994)

18. Brookstein D.S., Tsiang T.-H.: Load-deformation behavior of composite cylinders with integrally-formed braided and with machined circular holes. J. Compos. Mater. 19(5), 476-487 (1985) 
19. Wang Y.: Bearing behavior of triaxially braided flat and tubular composites. Appl. Compos. Mater. 1(3), 217-229 (1994)

20. Gautam M, Potluri P, Ogin S, Jain P.: Necking behaviour of flattened tubular braided composites. 20th International Conference on Composite Materials, 19-24th July 2015, Copenhagen (2015)

21. Gautam M. et al.: Hybrid composite wires for tensile armours in flexible risers: manufacturing and mechanical characterisation. Compos. Struct. 150, 73-83 (2016)

22. Torayca T700s Datasheet, Technical Data Sheet No. CFA-005, Toray Carbon Fibers America, Inc., Nov. 2002.

23. Lin H, Brown LP, Long AC. (eds): Modelling and simulating textile structures using TexGen. Advanced Materials Research, Trans Tech Publ (2011)

24. ASTM D5961/D5961M: Standard Test Method for Bearing Response of Polymer Matrix Composite Laminates. ASTM International, West Conshohocken, PA, USA (2010)

25. Araldite LY564/Aradur 2954 Hot Curing Epoxy System Data Sheet, Huntsman Advanced Materials GmbH, Jul. 2007. AQ3

26. ASTM D3171: Standard Test Methods for Constituent Content of Composite Materials. ASTM International, West Conshohocken (1999) AQ4

27. Ataş A., Soutis C.: Subcritical damage mechanisms of bolted joints in CFRP composite laminates. Compos. Part B. 54, 20-27 (2013)

28. Fahr A. Ultrasonic C-scan inspection of composite materials. (1992) AQ5

29. Hasiotis T., Badogiannis E., Tsouvalis N.G.: Application of ultrasonic Cscan techniques for tracing defects in laminated composite materials. Strojniški vestnik-Journal of Mechanical Engineering. 57(3), 192-203 (2011) 
30. Argon A.: Fracture of composites. Treatise on materials science and technology. 1, 79-114 (2013) 